\title{
RETHINKING THE TEACHING OF LAW
}

\author{
RICHARD JOHNSTONE*
}

\section{INTRODUCTION}

The Senate Standing Committee on Employment Education and Training's recent Report on Priorities for Reform in Higher Education commented that Universities have produced law graduates who "are usually well grounded in the knowledge and skills essential to the practice" of the legal profession, but who

are not familiar in any disciplined sense with the society in which they are going to practise their chosen profession, who are not analytical, creative thinkers, whose education does not provide the basis for adequate flexibility, who are not sufficiently attuned to the need for "lifelong" learning, and who are not good communicators. ${ }^{1}$

In short, the Committee noted, "Australia is producing highly training technicians who are under-educated in the broader sense of the term". ${ }^{2}$ A major factor highlighted by the Committee was the low quality of teaching in the education sector. ${ }^{3}$ It is difficult to argue against these comments made by the Senate Committee, and their application to law teaching in Australian Universities. They substantially describe my own experience as a law student, researcher and teacher in law schools since 1980. The focus of law teaching in university law schools, with a few notable exceptions is narrow, focusing primarily on exposition of legal doctrine, and rather halfheartedly, its application, with scant regard for the history, philosophy and political economy of the society within which law is practised and enforced. Despite some undoubted progress during the last few decades, law schools still have some way to go to break down the strong focus of professionalism and specialisation, where "knowledge has become cut up into 
innumerable separate parcels", with a "specialist profession" as "custodian and user of each of these parcels". 4

A few years ago, in a perceptive article about the history of legal scholarship in Australia, Chesterman and Weisbrot pointed out that Australian legal scholarship has been "predominantly positivist” and unquestioning, eschewing any recognition of legal pluralism. ${ }^{5}$ A major factor encouraging the development of this approach has been the particularly close link between legal education and the legal profession. ${ }^{6}$ Until recently, university law faculties were "generally viewed as adjuncts to the legal profession, rather than truly academic institutions dedicated to liberal educational aims". ${ }^{7}$ Law teaching was carried out mostly by practitioners, and there were very few fulltime academics. Little legal research was done, and the general approach in courses taught was fairly uniform. ${ }^{8}$ What distinguished Australian legal education from the English system was that the professional authorities did not themselves take responsibility for the "practitioners" subjects such as Evidence, Procedure and Conveyancing. Instead the law schools became "trade schools" providing almost all of the substantive law courses required for admission to practice. The professional authorities were not prepared to accord recognition for professional entry purposes to a university law degree unless it had a substantial "hard law" content in subjects directly relevant to legal practice. ${ }^{9}$ As Chesterman and Weisbrot noted:

Australian university law schools, having won the right to be the principal providers of legal education and socialisation, also inherited the imperatives of practice from the profession. This included the empiricist tradition of English legal training, with its emphasis on pragmatic, inductive reasoning, and its lack of concern for sociological jurisprudence. $^{10}$

Consequently what Australian legal texts there were, were marketed as being appropriate for both professional and academic purposes, and entirely academic, non-professional books on law were rejected by publishers on marketing grounds. The bulk of Australian legal scholarship was firmly located in the positivist framework, stressing above all the identification and analysis of "black letter” rules, ignoring multidisciplinary perspectives. Since the 1960s and the advent of fulltime academics, Australian law schools have begun to move away from this rigid "trade school" model towards the classic liberal model of university education, 
with law taking its place among the social sciences. ${ }^{11}$ But this movement has been retarded by the strong influence of the profession, both in terms of the continuing influence of professional recognition of the LLB degree, and the narrow legal training of most law teachers currently teaching in Australian law schools.

The impact of this on the method of law teaching in Australian law schools has been profound. The majority of Australian law teachers have adopted an approach to law teaching that has focused on teaching students "what the law is" in the hope that they will be able to then "apply" the law so "learnt" to a set of facts in a problem in the examination set at the end of the course. The principal and traditional teaching method has been for law teachers to adopt an expert and authoritarian role focusing on the 'lecture", typically fifty minutes of largely uninterrupted discourse from the teacher with no discussion between students and no student activity other than listening and note taking. ${ }^{12}$ Of course, some teachers have modified this style by attempting to use the "case book method" and some sort of "Socratic dialogue" with students. ${ }^{13}$ The Socratic model has been borrowed from law schools in North America, but has very few rigorous adherents in Australia. Many law teachers intersperse a straightforward lecturing style with questions directed at students, with some underlying intention of facilitating a degree of "student participation", although often the purpose of this "participation" is not clear. There is very little attempt to vary the skills acquired by students in the different courses. In essence, the same rules based course is taught over and over again - the only thing that changes in each case is the substantive law being studied.

This traditional model of law teaching has been shaped by a number of factors, the most important being that Australian law teachers, like most other tertiary teachers, are not required to have any teacher training. They have subsequently based their approach to teaching on the way they were taught at law school, an approach going back to the days when practitioners delivered lectures about legal rules that did not change as rapidly as they do today, and when legal pluralism was not embraced. This approach has been reinforced by a couple of myths held by law academics about education, and legal education in particular. 
The first myth is that it is difficult to ascertain criteria of "good teaching”. Consequently, teaching skills have been largely ignored in decisions about the recruitment and promotion of academics and there have been very few attempts to provide academics with the means to improve their teaching. Law teaching seems to have somehow ignored developments in educational theory, particularly in instructional psychology. ${ }^{14}$

The second myth is that law teachers cannot teach students a critical perspective on the law until "they know what the law is". This pre-empts the issue. By teaching the positive law uncritically and in the traditional authoritarian fashion, students are inculcated with an attitude to law and legal education that reinforces an uncritical, authoritarian acceptance of law as a series of rules. Once this ideological groundwork has been done, interdisciplinary approaches to law are then seen as "lacking in rigour" or "soft options" which are not central to legal education, and which can be, and usually are, discarded from law courses. Once again the narrow focus of law academics reproduces the same attitudes in law students, with the consequence that the central ideologies in legal practice are legitimised and reinforced.

This approach is reinforced by the narrow legal training generally accorded to law academics who develop competence in 'legal doctrine, but are not trained in legal theory or interdisciplinary approaches to law.

It has been enhanced by a tendency of career law academics to focus on the content of the law in order to equip students with "a knowledge of the law" so that they can be competent practitioners. ${ }^{15}$ This professional focus is a means of legitimising the work of law academics, who have tended to see their roles as being involved in professional training, instead of in education.

A problem familiar to all law teachers is that students appear to be disinterested in learning, or hostile to working for and during class. Most law teachers would sympathise with John Broadbent ${ }^{16}$ who quotes a vivid (but male focused!) description of the problems of being a university teacher:

One feels, as a teacher, rather like a soccer referee who having blown his [or her] whistle for the kick off, finds the players disconcertingly reluctant to make a move and is reduced to dribbling the ball himself [or herself] furiously from end to end, scoring brilliant goals in undefended nets, while the motionless players look curiously on. Yet it is arguable 
that one of the reasons for this frustration is that the teaching methods used in tertiary institutions, particularly in law schools, are inadequate and fail to motivate students to learn. The rest of this paper will explore this issue.

\section{WHAT SHOULD LAW SCHOOLS BE DOING?}

A university course should do more than train lawyers in the professional skills required for lawyering. Many law graduates in fact do not enter the legal profession. They end up working in universities, in other professions, or in the public service, where they may be concerned largely with issues of legal policy. While legal education has to have as part of its focus, the lawyer's pragmatic rationalisations of legal rules into more or less systematic form, ${ }^{17}$ it should never lose sight of the fact that law and lawyers operate in a complex society, which is governed by nonlegal as well as legal norms.

Learning about law involves seeing law as a phenomenon located in society and history, inter-connected with other political and cultural institutions and the subject of philosophical theories and debates. Legal phenomena can be studied and analysed from all sorts of perspectives and legal education should be concerned with equipping students to perform these tasks. Above all, legal education should be just that - an education, not narrowly focused training. At the bare minimum, good law teaching should enable students to achieve a broad range of learning objectives.

What then are the kinds of objectives that should be pursued in legal education? There are three kinds of objectives relevant to law teaching.

\section{Cognitive and Skills Objectives}

(1) Law schools need to consider how best to achieve the traditional objectives of legal education. At the basic level, legal education should develop basic knowledge and skills to equip students to be lawyers. In other words, students should be taught professional modes of thinking. These have always included requiring students to:

(a) Know and understand the basic elements and principles of important and basic areas of the substantive law. All lawyers need to know the basic principles of private and 
public law, whether they be derived from cases or statute. One of the great problems in traditional legal education is that students have been expected to learn, by rote in many cases, a huge amount of detailed material. Students do not need to know every legal principle, or every important case, even within a particular area. They need to know the important principles in the important areas, and the way that these principles relate to other subject areas. Students should be taught a basic framework of principles and the skills to "flesh out" the detail of these principles. ${ }^{18}$ Students should also be taught how to learn the skills involved in learning for themselves the basic principles of an area with which they are unfamiliar, so that they can themselves build up their own required level of detail.

(b) Understand the likely future developments in the substantive law. This is an important skill for legal practitioners, which will enable them to give good legal advice that will enable clients to structure their affairs taking into account future developments in the law. It is also an important intellectual skill in its own right. Legal expertise involves an ability to assess the likely future developments in a particular area. An understanding of the future development of legal principles requires learning that focuses on the history and context of the legal principles, and the internal tensions in the principles and their operation in society, so that their future development can be anticipated, at least in broad outline.

(c) Analyse cases, facts, statutes and documents. Analysis essentially involves breaking down the subject matter into its basic components and examining the relationship between these elements. Students should be able to read a case properly, by analysing the basic facts of the case, and extracting the ratio decidendi and important obiter dicta. Similarly students should be able to read statutes, so that they can pick up any statute, understand its basic principles and predict the way in which they will be interpreted by the courts. Students 
should also be taught how to elicit, analyse and interpret basic facts from a client. Clients have their own narratives which they are keen to give to lawyers, but which contains a lot of detail which is irrelevant to the legal solution to the problem, but is very important to the client. Lawyers need to be able to discern the important facts in any situation and ask questions to get further relevant facts, but at the same time listen to and respect the needs of the client which emerge from the clients emphasis in relaying the facts. This is a skill not traditionally taught in law schools.

(d) Apply legal principles, and their likely practical implementation, to the "facts" of a particular problem. This is a crucially important skill for lawyers. Traditional legal education has required students to apply legal principles to facts but has ignored the more sociolegal issues relating to the way that the law is implemented or enforced in practice. In other words, how do prosecuting authorities enforce the law and how do legal practitioners resolve civil law disputes? How do courts exercise sentencing discretions? Traditional legal education has also restricted the kinds of applications that students have been taught. Students, for example, are rarely taught how to apply their knowledge of the substantive law to draft documents, such as contracts or wills.

(e) Synthesise the legal principles emerging from cases and statutes, and the practice of legal agencies and practitioners. This involves students putting together the component parts of the law into a new form for a particular purpose. Students can be asked to write judgements to resolve the dispute before them, or to prepare the argument for one of the parties, or to advise one of the parties of their legal rights in the problem, the likely outcome of the dispute, and the strategy they should utilise in trying to resolve the dispute. They can be asked to synthesise their understanding of an area by drafting a document or clause of a document.

(f) Evaluate the internal logic of an opinion, judgment, 
statute, empirical study of the law in operation, or any other analysis of the law. Is the analysis consistent within its own terms? Are the arguments internally coherent? Does the evidence presented by the writer support her or his conclusions?

(2) There are other cognitive skills and objective to be achieved in law schools. Less traditionally, legal education should also link the study of law to other disciplines in the humanities and the social sciences. In other words, at least as an intellectual activity, but also arguably as an important practical legal skill for policy makers, lawyers should be able to relate law to other university disciplines. Law operates in a complex society. It is a social phenomenon laden with values, ideologies and complex histories. Legal education should equip students to examine the role of law in that society by utilising relevant perspectives from the social sciences (particularly feminist analysis, sociology, political science, economics and anthropology) and the humanities (particularly history and philosophy). This will require lawyers to familiarise themselves with the basic frameworks and methodologies in these disciplines and to apply them to legal phenomena.

A major benefit of these interdisciplinary perspectives is that students will learn different types of reasoning. In working towards the different objectives described in the previous section, students will largely develop “conditional reasoning” skills, or reasoning skills using deductive logic, such as the "material conditional" "if p, then q". ${ }^{19}$ Practical work in the social sciences, particularly in economics and the sociology of law, will enable students to develop statistical ${ }^{20}$ and methodological ${ }^{21}$ reasoning skills. This has the important consequences of broadening the reasoning skills ${ }^{22}$ learnt by students in the law degree. ${ }^{23}$

(3) Law should always be taught within the context that it operates within a complex society. Law has an impact on that society, and its content and practice is shaped by that society. Interdisciplinary studies can be used to show the impact of law on different groups within society, and the impact of different groups, depending on their power, on the law. 
Students should be encouraged to ask who benefits from different aspects of the law; who is disadvantaged; who has best access to the law; whose rights are ignored by the law and similar questions.

(4) In learning all these different cognitive skills, students should be encouraged to develop important communication skills, whether written or oral. Law students also need to develop research skills, as well as their ability to work with other people. Face-to-face communication skills are important and can be exercised in many contexts, including class discussions. Students should also be developing skills in communicating with people who are not lawyers or who have speech, hearing, visual or other impairments. Equally important is the ability to work creatively and constructively with other people, to be open-minded, to be willing to have a point of view challenged and to question other viewpoints, and to understand and accept other cultures. Students should also be encouraged to learn how to listen to others, to work together in a team, and to learn to think creatively.

A very important skill for lawyers of all types, from practitioners to researchers and teachers, are library research skills. Legal library research methods should be taught and practised at all stages in the law degree. These research skills are important aspects of all the cognitive skills discussed above.

\section{Objectives Relating to Values}

Law students should not just be taught different cognitive skills. I have already argued that law cannot be considered merely as a closed formalistic, logical structure. Certain values and ideologies are "built into" legal doctrine, procedures, institutions and practice, and our personal attitudes and values will shape our response to law and the activities of lawyers. Legal education needs to provide the opportunity to explore these ideologies, attitudes and values, and should enable students to develop their own attitudes, values and interests in an environment that is not only supportive of this process, but also challenging and exciting.

Students should be encouraged to consider and explore the values explicitly and implicitly contained in the law and its practice. In short students need to be able to "think like lawyers" 
and at the same time stand back and reflect on "how lawyers think.

Equally important is the provision, in a well designed curriculum, of opportunities for students to develop their own system of values pertaining to legal education, legal practice, and the role of law in regulating society's affairs. All law students should be able to develop their own values about the law in a challenging but supportive learning environment.

\section{Motivational Objectives}

An important objective of legal education, which strongly supports the other objectives discussed in this section, is the motivation of students to learn, to explore all aspects of legal phenomena, and constructively to criticise legal rules, their application in practice, theories about the law, and legal education. Recently there has been much research into self-directed learning. ${ }^{24}$ Adult educators have argued that learning is an internal process, self-initiated and intrinsically motivated. The only learning which significantly influences behaviour is self-discovered, selfappropriated learning. ${ }^{25}$ Legal education should not just enable the student to learn about the law in all the different aspects discussed above, but should involve freeing the learner from dependence upon traditional pedagogical methods, and enabling the learner to learn how to learn. But, as Chene notes, "to know how to learn, one has to have learned ... [O]ne cannot rely on oneself unless the norms and limits of the learning activity are known." ${ }^{26}$ Before learners can direct their own learning, they have to be introduced to the tradition of knowledge.

A well structured law course should enable students to meet all of these objectives. ${ }^{27}$ This requires teaching to be well planned, well executed, and focused on not only developing cognitive skills but on inspiring students to carry out an evaluation of their values and the values implicit in the law and critical examination of all aspects of their learning. Educational objectives can be pursued both in and outside class, in instructional materials designed for independent learning, in a student's choice of readings, essays and the issues raised in class discussions, classroom activities, and in daily interaction with other students.

In summary, by focusing on legal education in the context of well accepted learning objectives, it is quite clear that law schools 
cannot continue to orientate their courses to the basic cognitive skills such as knowledge and comprehension. Instead there needs to be a careful reorientation to develop the other sorts of skills and objectives outlined above.

The argument that will be pursued in the rest of this paper is that without a more informed, careful and skilled selection and utilisation of teaching methods in law classes, it is unlikely that these broader instructional objectives can be achieved. The argument will focus on further defining what is meant by good teaching. I will begin by looking at a recent development in instructional theory. I will touch upon the many styles of learning and attitudes to learning. I will argue that law teachers will need to teach in a variety of styles in order to accommodate these different ways of learning, and the different instructional objectives. The last part of this paper will tie together the different instructional objectives, learning styles, teaching styles, with the different methods, techniques and devices available for use in law classes.

\section{WHAT IS GOOD TEACHING?}

The starting point for any discussion of the notion of "good teaching" is that it means those activities and attitudes which encourage high quality learning. Learning is a process of change, in which learners move from their current state of knowledge to a greater understanding of a subject or topic. Learning builds on the learner's background and previous learning, and expands and deepens her or his awareness and understanding. Learning is part of personal growth and development and can only be carried out by the learner. While teachers also learn from joining the process of learning/ teaching, their function is essentially to facilitate learning. Joint responsibility for learning lies with the learner.

Ramsden argues that " $[\mathrm{t}]$ here is a cherished academic myth that good teaching in higher education is an elusive and ultimately indefinable quality. The reality is that a great deal is known about its characteristics." 28 So far I have suggested that "good teaching" begins with clearly defined and comprehensive teaching objectives that are based on the competencies we want our students to achieve before they leave law school. Ramsden further notes that the research findings indicate that good teaching involves being at home with one's subject and being enthusiastic about sharing one's 
love of it with others. It includes using clear explanations to students, but more importantly it implies making the material of the subject genuinely interesting, so that students take great pleasure in learning it. An essential part of good teaching is the showing of concern and respect for students. This requires teachers being available to students, and giving students high quality feedback on their work. It means being quite clear on what students have to learn, and what they may leave aside. It also means working at the level of the students. It entails a demand for evidence of understanding by students, the use of a variety of techniques for discovering what students have learned, and an avoidance of assessment that requires students to rote learn or merely to reproduce detail. ${ }^{29}$

Ramsden also notes that good teaching:

usually includes the application of methods that we know beyond reasonable doubt are more effective than a diet of straight lectures and tutorials, in particular methods that demand student activity, problem solving and cooperative learning. Yet it never allows particular methods to dominate. There are no simple means to simple ends in something as complicated as teaching... Good teaching is not a series of methods and recipes and attitudes, but a subtle combination of technique and way of thinking, with the skills and attitudes taking their proper place as vital but subordinate partners alongside an understanding of teaching as the facilitation of learning. ${ }^{30}$

Good teaching requires an ongoing evaluation by the teacher of the effect of the teaching on the learning of students, and modifying the teaching in the light of the information collected. ${ }^{31}$

Good teaching should not simply require students to be receivers of information, but should engage them in testing ideas, and exploring issues, problems and values. In particular, good teaching does not rely heavily on "lecturing" or any other expository teaching methods. Student independence should be encouraged — students should not be dependent on information imparted by teachers, but should rather feel free to enquire and to explore ideas, solutions and values. The teacher's role should be to prepare the relevant materials, to facilitate learning, and to ensure that the atmosphere in the class is conducive to creative, nonthreatening discussion. This is only possible if the factors which inhibit learning are minimised. These factors include aggressiveness, over-competitiveness, insensitivity, racism, sexism, and authoritarian behaviour. They all inhibit learners from "taking 
risks” in order to learn.

Good teaching also takes account of the fact that not all students have the same way of learning. For example, one branch of the literature $^{32}$ identifies different stages of the learning cycle and notes that different people have different strengths and preferences in the way they learn. The four stages of the learning cycle are: ${ }^{33}$

- learning by concrete experience, which emphasises personal involvement with people in everyday situations and relies more on the learner's feelings than on a systematic approach to problems and situations.

- learning by reflective observation which involves learning by watching and listening and viewing things from different perspectives. The learner relies on her or his own thoughts and feelings to form opinions.

- abstract conceptualisation where learning involves using logic and ideas, rather than feelings to understand problems and situations. The general approach here is to rely on systematic planning and on developing theories and ideas to solve problems and

- learning by active experimentation in which learning takes an active form and the learner has a practical approach and a concern with what really works, instead of watching things being done. Learners favouring this mode value getting things done and seeing the results of their efforts. ${ }^{34}$

Learning best takes place with the learner moving through all four of these stages, although usually individuals will tend to favour one of the stages. Consequently, each person's learning style will be a combination of these four learning modes.

For example, “convergers" combine the learning steps of active conceptualisation and active experimentation, and are best at finding practical uses for ideas and theories, and at solving problems and making decisions. They prefer technical tasks and problems rather than interpersonal issues. Their weaknesses tend to be a tendency to make hasty decisions, a lack of focus, and insufficient testing of ideas. ${ }^{35}$

"Divergers" combine the learning steps of concrete experience and reflective observation. They observe rather than take action, and are best at viewing concrete situations from many different points of view. Their strengths are generating a wide range of ideas, 
imaginative ability and sensitivity. They have broad cultural interests and like to gather information. Divergers are often paralysed by alternatives and often find it difficult to make decisions. $^{36}$

"Assimilators" combine the learning steps of abstract conceptualisation and reflective observation, and are best at understanding a wide range of information and putting it into concise logical forms. Assimilators are less focused on people and more interested in abstract ideas and concepts. They find it more important that a theory have logical soundness rather than practical value. Interestingly, it is said that this learning style is most suited to academics and lawyers. Assimilators are usually criticised as being too abstract with no interest in practical application, and unable to learn from their mistakes. ${ }^{37}$

"Accommodators" combine the learning steps of concrete experience and active experimentation, and have the ability to learn primarily from "hands-on" experience. They enjoy carrying out plans and being involved in new and challenging experiences, and act more on "gut feeling" rather than logical analysis. Their approach to problem-solving relies more heavily on people for information, rather than on technical analysis. Accommodators often are not sufficiently directed towards goals, have impractical plans and have difficulty meeting deadlines. ${ }^{38}$

There are a number of implications from this oversimplified, but useful, description of learning styles. Well rounded lawyers need to have skills from all of the learning styles, and therefore cannot afford to have learning styles that are too "unbalanced". At the same time it is quite clear that most students and in fact most teachers, have strong preferences towards one or other learning style. Law students with unbalanced learning styles will also find themselves unable to meet the learning objectives outlined earlier in this paper. Good teachers therefore need to vary their teaching styles and methods to develop student's ability to learn in different ways, so that students develop all-round learning, problem-solving and decision-making skills. Students should therefore be challenged to develop different learning styles.

On another level while students will respond very well to the styles of teaching that "fit" their learning styles, they will not cope well with teaching styles biased away from their learning strengths. 
Teachers who are locked into a particular style and project that style into their teaching, will find that they are favouring some students and severely disadvantaging others. It is therefore imperative that law teachers learn to teach using a variety of teaching styles and methods.

Before moving on to a discussion of a choice of teaching styles and methods appropriate to meet the learning objectives and styles discussed in this paper, it should be noted that not only do students differ in their styles of learning, but they differ in their attitudes to classroom learning. The literature ${ }^{39}$ identifies a number of categories of student. Some of the more relevant types are as follows. ${ }^{40}$

“Compliant” or "participant” students are content with their lot, and work because their parents expect them to, and because they will be assessed at the end of the course. Their main concern seems to be to understand the material and they are most comfortable with the most basic cognitive objectives. They are task orientated and try to get as much out of the class as they can. They participate when told to do so, but they are unimaginative. They will be concerned when faced with a teaching style which involves the teacher relinquishing too much control.

A second category is well known to Australian law teachers and forms a large part of most law classes. These are what Mann calls the "anxious dependent" students, ${ }^{41}$ angry on the inside and mostly frightened on the outside. They are very dependent on the teacher for knowledge and support, and very anxious about being assessed. Members of this group tend to regard themselves as being intellectually incompetent. Their anxiety prevents them from doing any constructive work in the classroom, and they exert enormous pressure on teachers to "spoonfeed". These students show little intellectual curiosity and learn only what is required.

"The independents", generally older students, are confident of their own ability, and are not threatened by the teacher, the work, or other students. These students like to think for themselves and work with class material in creative ways. They favour collegiate relationships with teachers, but also want to keep the roles of teacher and student quite separate.

A fourth category is labelled by Mann as "the heroes". For them, classwork is closely tied to rebellion and they distrust 
authority. They can be at the same time, very productive and creative, but also hostile and resentful. They often see themselves as superior, and express contempt for their "ordinary" classmates and for "common people" involved in the material they study in and outside the classroom.

A fifth category is what Mann calls the "snipers". They have a low level of self esteem and feel rebellious. Their non involvement generally derives from their pessimism at the possibility of a worthwhile relationship with authority figures. They snipe at the teacher from a distance, are hostile, but very rarely move toward the teacher and are elusive when the teacher wants to confront them directly on an issue.

“Attention seekers” have a predominantly social rather than intellectual orientation. They are preoccupied with pleasing the teacher and their classmates. This often involves frequent talking, bragging, showing off and joking. Their need to be accepted overshadows their intellectual development and they are uncomfortable if the teacher leaves them to their own intellectual devices.

"Silent" students do not participate verbally, and experience a tremendous sense of vulnerability in relation to the teacher.

"Competitive" students learn material in order to perform better than others in the class. This kind of student views the classroom as a win-lose situation, where the student must compete with others for the teacher's attention, and for good marks.

"Collaborative" students believe they can learn the most by sharing their ideas and talents. They co-operate with teachers and peers and like to work with others. They see the classroom as a place for social interaction, as well as a place for learning content and skills.

"Avoidant" students are not interested in learning course content in the traditional classroom, and will not participate with the teacher and fellow students in the classroom.

Of course these descriptions of the different types of attitudes and learning styles are by no means the only possible categorisations. The descriptions are given merely to highlight the diversity of styles and attitudes in the classroom, and to emphasise that good teaching should also recognise that not only do students have different learning styles, but they have different temperaments 
and attitudes to learning.

Often these attitudes to learning and participation in the classroom are closely tied up with issues of gender, and it is crucial that this be recognised and that teaching methods introduced to prevent these gender stereotypes being reproduced in the classroom. $^{42}$ Students also have different class and cultural backgrounds, and differing political attitudes. The traditional approach to law teaching has a predominantly white middle/professional class Anglo Celt male orientation, so that it is heavily slanted towards reinforcing attitudes consistent with this focus and preserving the status quo, both in broader Australian society and in the legal profession. Good law teaching needs to make itself relevant to other groups of students - women students, students from different cultural backgrounds, students from working class backgrounds, students with physical or other impairments, and students with more "progressive" political orientations. Not only should they be accommodated in legal education, but students from the law schools' traditional recruiting ground should be exposed to issues of gender, class, race and disability, and be made to realise the diversity of Australian multiculturalism.

\section{TOWARDS THE DEVELOPMENT OF AN APPROPRIATE TEACHING MODEL OF LAW TEACHING}

The challenge that this paper has thus far set up is for law teaching to free itself from its narrow cultural and "content focused" orientation, and to develop a more varied teaching model, which uses different styles of teaching, varying teaching methods, focusing on the different learning objectives, and within a number of theoretical frameworks. While this is clearly a daunting task, it is far from impossible.

Firstly, there are a number of different styles of teaching available to law teachers. Each will be more suitable to facilitate the achievement of particular learning objectives, and each will be more appropriate to accommodate and develop particular student approaches to learning. Once again the educational literature identifies a wide variety of teaching styles.

One style is what can be called the "teacher as expert". Here the 
teacher is the "expert", at least within the framework of the course content and the style focuses on the disparity between teacher and student with respect to the knowledge, experience and the wisdom each can apply to the subject matter of the course. ${ }^{43}$ The teacher is accepted because of her or his authoritative knowledge and experience - that knowledge legitimises her or his position, and tempers consciously or unconsciously, student attitudes to learning.

A second style is the teacher in the role of a formal authority ${ }^{44}$ or in Adelson's terms, the teacher as priest. ${ }^{45}$ Here the teacher claims authority through her or his office. S/he is an agent not only of instruction, but of control and evaluation and is responsible to a group of administrators and external agents who expect her or him to ensure uniformity of standards and merit based grades at the end of the course.

A third style is the teacher as "socialising agent" 46 where the teacher acts as a recruiter in her or his field, with an eye out for students with ability. The teacher plays the role of assisting students to undertake postgraduate work, academic positions, or other positions in the community.

A fourth style is the teacher as "facilitator" 47 or in Adelson's terms, the teacher as "mystic healer". ${ }^{48}$ This style is strongly centred on the students and their aspirations, instead of on the teacher's expertise and power. The teacher aims to ascertain what student goals and objectives are, what they can achieve at present, and what they might need to help them to do better. Typically this will involve the teacher in doing more listening and questioning then lecturing and assigning. The teacher will have to vary her or his approach according to the phase of teaching and the student sometimes lenient, sometimes stern, sometimes encouraging, sometimes critical.

A fifth style is what Mann calls the "teacher as person". ${ }^{49}$ Here the teacher aims at engaging students in a mutually validating relationship. This approach aims at developing an atmosphere of trust and freedom so that both student and teacher can share their ideas, experiences and personal reactions not only to the course material but also to matters that may fall outside the traditional areas of concern in the classroom. These teachers learn as much from the students as they do from her or him. Whereas the teacher as facilitator focuses on developing the minds of her or his 
students, the teacher as person emphasises the personal development of the whole student, ${ }^{50}$ including attitudes, values and interests.

A final model is identified by Mann as the teacher as "ego ideal". ${ }^{51}$ Here students look up to the teacher, not so much as a discipline expert, but as a model for living, if not in all aspects of the student's life, then at least in some. By her or his energy or enthusiasm, this kind of teacher inspires students to find something that is as liberating and exciting as the teacher's work is for the teacher. In short, students use their teacher in the continuous process of formulating and approaching their ideals.

What emerges from these discussions of learning objectives, learning styles, and teaching styles, is that there are "three basic configurations" of teacher, student and content. ${ }^{52}$

First there is teaching and learning focused on content, where the primary aim is to cover the course material in a coherent and systematic manner, with the content of the various course within the discipline kept discreet, as is the case in most law schools. This approach relies on the teacher as expert or formal authority and best favours students who exhibit competitive or dependent learning styles and who are "assimilators". The course is defined by its content and materials, and principally utilises lectures and formal discussion as the principal teaching method. The course is largely content orientated, and uses the teacher as a source of information. $^{53}$

Secondly there is teaching and learning which focuses on the teacher. The teacher is not primarily a source of information, but as a model of the way in which a particular discipline should be approached. Here the teacher is a "performer", a "socialising agent" or "ego ideal", and can sometimes be labelled as "charismatic". Where lecturing is used, it is used dramatically; when discussions are utilised, they are directed towards the teacher. Student reactions to this approach will vary - dependent students will embrace it uncritically, and participant students will approve if the teacher appears competent. The course may be cognitively orientated but will often have some focus on values. ${ }^{54}$

Thirdly, there is teaching and learning which is centred on students. This emphasises the intellectual training .and/or personal growth of students. The teacher essentially adopts a "teacher as 
facilitator" and a "teacher as person" style in relation to students who are principally collaborative and independent. The avoidant student will also benefit if s/he gives the experience a chance. In this mode of teaching the teacher and students together define specific learning goals, resources and means of evaluation which may be tailored for each student. Teaching methods will focus on student-run discussions, group discussions, role plays, simulations, field work, and independent study. Learning will focus on cognitive, values, motivational and skills objectives. ${ }^{55}$

From this it is apparent that good law teaching requires law teachers to be proficient in a number of teaching styles, and to be able to utilise various methods. Developing a basic approach to law teaching which combines these styles and counters the weaknesses of the traditional approach to legal education is complex, but recent developments in instructional theory provide some very important pointers as to the direction that law teaching might take. These developments suggest that teaching should revolve around notions of "situated learning" and "cognitive apprenticeship". These concepts are explained in the rest of this section.

Seely Brown, Collins and Duguid suggest that the perceived breach between learning ("know what") and use ("know how") may be the product of the structure and practices of our education system. ${ }^{56}$ Many methods of didactic education, including traditional legal education, "assume a distinction between knowing and doing, treating knowledge as an integral, self-sufficient substance, theoretically independent of the situations in which it is learnt and used". ${ }^{57}$ The primary concern of traditional legal education is with the transmission, by the lecture method, of abstract, decontextualised formal concepts. The activity and context in which learning takes place are regarded as secondary to this primary function.

Seely Brown, Collins and Duguid report that recent investigations in learning challenge this separation of what is learned from how it is learned and used. It is now being argued that far from the activity in which knowledge is developed and deployed being separable from or ancillary to learning and cognition, or in any way neutral, it is an integral part of what is learnt. "Situations might be said to co-produce knowledge through activity". ${ }^{58}$ Situations structure the process of gaining knowledge. 
Concepts are not abstract, self-contained entities. New situations and activities will recast the concept in a new, "more densely textured form”.

Seely Brown, Collins and Duguid argue that by "ignoring the situated nature of cognition, education defeats its own goal of providing usable, robust knowledge", 59 and instead will produce only "inert" knowledge. They argue that approaches that embed learning in activity and make deliberate use of social and physical context are more in line with the understanding of learning emerging from current research. They suggest that conceptual knowledge is similar in many ways to a set of tools, in that they both can only be fully understood through use, and using them entails both changing the user's view of the world and adopting the belief system of the culture in which they are used. ${ }^{60}$ It is possible to acquire a tool but be unable to use it. Similarly it is possible to acquire decontextualised knowledge, and even carry out exercises with that knowledge but be unable to use it in a truly practical sense.

Learning how to use conceptual tools involves far more than just receiving a set of explicit rules for use. The occasions and conditions for use arise directly out of the context of activities of each community that uses the tool, framed by the way members of that community see the world. The community and its viewpoint, quite as much as the tool itself, determine how a tool is used”. ${ }^{61}$

In short, activity, concept and culture are interdependent. Learning must involve all three. Academic disciplines and the professions, are communities with cultures, bound by intricate socially constructed webs of belief, which are essential to understanding what they do. ${ }^{62}$ The activities of these communities can only be understood if they are viewed from within the culture.

We should avoid teaching methods that impart abstracted concepts as fixed, well defined, independent entities that can be understood by prototypical examples and text book exercises. Students too often are asked to use the tools of a discipline without being able to adopt its culture. Often they are only shown one culture during their university careers - the culture of university life. The way that universities use the tools of these disciplines can be different to the way that practitioners use them. Students can thus pass exams, but still not be able to use the discipline's 
conceptual tools in authentic practice. As Seely Brown, Collins and Duguid comment, they need "to be exposed to the use of a domain's conceptual tools in authentic activity — to teachers acting as practitioners and using these tools in wrestling with problems of the world" ${ }^{63}$

So what is "authentic activity"? Authentic activities are simply defined as the ordinary practices of the culture. ${ }^{64}$ For learners to discover inventive solutions to problems, they need to see the problem in the proper context, which itself is embedded in an ongoing activity. This is the way experts resolve problems. The problem-solver needs to be able to use the inventive and intuitive problem-solving skills used in everyday life and in the particular culture that is being explored. The adequacy of the solution should become apparent in relation to the role it has to play in allowing activity to continue. Authentic activity can tease out the way lawyers, historians or legal theorists look at the world and solve emergent problems.

Good teaching should therefore embrace methods involving "cognitive apprenticeship". 65 These methods try to "enculturate" students into authentic practices through activity and social interaction in a way similar to craft apprenticeships. They enable students to acquire, develop, and use cognitive tools in authentic domain activity. ${ }^{66}$ This kind of process enables apprentices to enter the culture of practice.

An instructional approach to law teaching using cognitive apprenticeship methods should try to generate legal, economic, feminist, sociological etc practice, show students how to think about the world in those frameworks, how to see the world through the eyes of those who practice in those disciplines, and how to use their tools. This means more than simply giving students problemsolving strategies. ${ }^{67}$ It should provide students with the opportunity to enter the culture of legal, sociological etc practice.

Seely Brown et $\mathrm{al}^{68}$ list procedures that are characteristic of cognitive apprenticeship.

First, the task is embedded in familiar activity. This will show students the legitimacy of their everyday knowledge and its availability as scaffolding in apparently unfamiliar tasks. An excellent example of this in the law of contract is to require students in their first class to negotiate the drafting of a contract to 
protect the interests of their client or to look closely at a contractual clause which is part of a contract in everyday use.

Second, by pointing to different approaches to the problem, the teacher shows that problem-solving approaches are not absolute, but assessed with respect to a particular task.

Third, by allowing students to generate their own solution paths, they are given a chance to be conscious, creative members of the culture of problem-solving lawyers, law and economics practitioners, sociologists of law etc. In enculturing through this activity, they acquire some of the culture's tools - a shared vocabulary and the means to discuss, reflect upon, evaluate, and validate community procedures in a collaborating process.

This approach can be extended by strongly emphasising the exposure of students to the authentic ways of thinking of a culture and its conceptual viewpoint, as much as to its subject matter. It is also useful for students to observe how practitioners at various levels behave and talk to get a sense of how expertise is manifest in conversation and other activities. Cognitive apprenticeship involves the student progressing from embedded activity to general principles of the relevant culture. Apprenticeship and coaching in a domain begin by:

providing modelling in situ and scaffolding for students to get started in an authentic activity. As students gain more self-confidence and control, they move to a more autonomous phase of collaborative learning, where they begin to participate consciously in the culture. The social network within the culture helps them to develop its language and belief systems, and promotes the process of enculturation. Collaboration also leads to articulation of strategies, which can then be discussed and reflected upon. This then fosters generalising, grounded in the students situated understanding. From here, students can use their fledgling conceptual knowledge in activity, seeing that activity in a new light, which in turn leads to the further development of the conceptual knowledge. 69

Students in law schools, like all apprentices, should therefore recognise and resolve the ill-defined problems that issue of authentic activity, in contrast to the well-defined exercises that are typically given to them in text books and examinations. Students should be behaving as practitioners and developing their conceptual understanding through social interaction and collaboration in the culture of the domain, not the school. Learning involves some form of social interaction, social construction of knowledge, and 
collaboration.

It is rare that law schools will be able to teach students in situations that are totally authentic. Nevertheless students can be involved in hypothetical situations that closely approximate the kind of work that legal practitioners and legal theorists engage in.

\section{TEACHING METHODS AVAILABLE TO LAW}

\section{TEACHERS}

Teachers have a number of teaching methods to choose from, and some are more conducive to student participation, to the development of values and attitudes, or oral, interpersonal, writing, research or intellectual skills than others. ${ }^{70}$ Most can be used to enable students to engage in the kinds of activities that lawyers, sociologists, legal philosophers, historians, economists etc will engage in, thereby grounding student learning in authentic, enculturated activity.

The most useful methods are as follows.

“Lecturing”. Lecturing is a good way of imparting a small amount of information quickly and concisely. It is well known, however, that the lecture is less valuable than other methods for stimulating thought and fostering higher level abilities. ${ }^{71}$ It encourages student passivity and involves the teacher taking responsibility for student learning (for example the well known student complaint that "the lecturer was not clear enough"). Lecturing therefore has very limited usefulness for teachers who are concerned to involve their students in "authentic activity".

The usefulness of lecturing is also limited because it relies wholly on the oral skills of the lecturer and the aural and recording skills of the student. A more efficient method of imparting information is through the written word (printed materials, required reading from books, cases, articles, printed problems or case studies etc ${ }^{72}$ ). Most students lose concentration after about twenty minutes of a "lecture". Consequently the most beneficial use of the "'lecture" method is in the form of a "mini lecture" of no more than twenty minutes before or after some other method is used. ${ }^{73}$ For example a mini lecture could precede a problem-solving exercise in small groups, or could follow a small group discussion on a particular topic, in order to pull together the salient points. 
Lecturing is greatly enhanced by the use of media particularly overhead projectors and whiteboards. Students will follow a lecture more easily if they are using more than one of their senses. Students will retain more knowledge attained through sight than aurally. ${ }^{74}$

"Buzz groups" or "small groups". Buzz groups allow total participation by class members, firstly in small clusters, and then in the resulting general discussion. The class is divided up into groups of two to six students and each group is given one or two questions to discuss for a certain period of time. At the end of that time, a spokesperson reports the group's conclusions to the class. Members of the group should take care to ensure that each member is introduced to the other members, that each person gets a chance to speak, and that the group elects a spokesperson.

The greatest strength of buzz groups is that they encourage active learning and can be used to achieve a number of objectives. Generally they can be used to draw out quiet students and to help them develop oral skills and give them a chance to talk about legal phenomena. They are an excellent method for involving students in authentic activities, such as problem-solving and project work. Students get a chance to explore a problem and to develop an approach to it. They are also useful for analysis and synthesis because groups can be asked to analyse a certain issue or doctrine, or to put together an argument. They often can be used to prepare for other type of activities - such as moots, debates, role plays and similar activities. And above all they develop skills in working with others.

Buzz groups can be abused and overused, particularly if they are used for their own sake, with no educational purpose. Students who are focussed on the more basic cognitive objectives often believe they are not learning anything in buzz groups, because the teacher is not giving them content. Good students can feel that they are not developing what they know because the rest of the group is not as well prepared, or as skilled as they are in working with the material. The good use of buzz groups involves the teacher being clear as to the purpose of the exercise, and communicating this to the class. Students who know the purpose of the activity will be in a better position to regulate their own learning. The teacher may also need to join the discussion in groups that are flagging, and may 
need to ensure that each group is on track with the activity.

"Class discussion". This involves the teacher seeking the comments and opinions of all class members in one discussion. This method can also be used to involve students in activities such as problemsolving. The teacher's role is to keep the discussion focussed on the topic, and moving at an appropriate pace. It requires students to discuss the topic, basing their contributions on pre-reading, their proposed solutions to a problem, and/or their own experiences. One disadvantage of class discussion is that it is often dominated by a small group of students, while the rest cannot or will not contribute. It is also difficult for the teacher to ensure that less assertive students build up sufficient confidence to participate in discussions. A key aspect of the good use of class discussion is that the teacher uses a variety of types of questions so that students are developing different cognitive skills during discussion $;{ }^{75}$ that the teacher learn how to draw out quieter students and prevent the more aggressive, insensitive or vociferous students from dominating the class, and that the teacher be prepared to reveal her or his own values, experiences and interests so that students are encouraged to do the same. Teachers should also learn to be aware of when to push a student to develop her or his contributions to the class, and when to encourage more reticent students to make contributions without threatening them with further questions. Class discussions are only valuable if the teacher ensures that all students speak loud enough to be heard by all members of the class. If this is not possible, the teacher should paraphrase the contributions of quieter students to ensure that continuity is maintained.

A very important aspect of class discussion, and of small group discussion, is the question originally asked by the teacher which is to become the focus of the discussion. Centra has divided the kinds of questions that can be asked into four types. ${ }^{76}$ Each type of question focuses on different cognitive skills and the higher level questions encourage students to explore values. At the lowest level are cognitive memory questions, where the intention is to have students recall or recognise information. These are narrow, closed questions which require a low level of thinking, and student responses can easily be anticipated. Students respond to these types of questions by recalling specific facts, defining, repeating, answering "yes” or "no”, or quoting. For example, a student can be 
asked to recount the facts of a case, or the elements of a cause of action.

At a higher level are convergent questions, which aim to have students analyse and combine given and remembered information. These are also narrow, closed questions, but require slightly higher level thinking and the answers, although generally predictable, are less restricted. A student responds to this kind of question by interpreting, comparing, contrasting, explaining, concluding or summarising information. An example of this kind of question is "How do the judicial decision-making models of Hart, Dworkin and MacCormick differ?"

Divergent questions aim to get students independently to develop their own information or view a given topic from a new perspective. These are broad, open-ended questions which permit a wide variety of thought provoking, original and unpredictable answers. To answer these questions, students hypothesise, speculate, predict, imply, synthesise, infer, devise plans and solve problems. An example is "devise a research methodology to determine how legislation might best lower the road toll”.

At the highest level are evaluative questions, where teachers intend students to project and support their judgments, values and choices. For the most part these questions involve the use of cognitive operations from all the other levels, and can also involve an exploration of the students attitudes, values and interests. They are broad, open-ended questions, with diverse and unpredictable responses. In answering these questions students judge, value, choose, rate and offer opinions. A student should be challenged to defend her or his opinion by using internal and external standards. An example of this kind of question is "who is your favourite judge? Why?” Lower level questions can be used to get discussion going, and as a prelude to higher level questions.

Good teaching requires teachers to ask questions at different levels of this spectrum. If necessary, students should be given time to jot down answers and thoughts in response to a higher level question before responding orally.

During class discussions, the teacher should ensure that particular groups of students are not discouraged from speaking in class. ${ }^{77}$ If students do not feel they can contribute in class, they will lose the educational benefits of class discussion, particularly the 
opportunity to develop oral skills. Women and Asian students for example, are quieter in the law class because of social conditioning, and teachers need therefore to address their teaching techniques to that issue. Teachers need consciously and sensitively to invite women to speak in class, to facilitate their participation, and to try as far as is possible, to remove inhibiting factors. One technique ${ }^{78}$ is to facilitate participation by asking students to forget themselves, and to play a role - "What would you argue if you were counsel for the plaintiff?”. Another approach ${ }^{79}$ is, when a student is stuck with an answer to a question, to ask whether she would like assistance from another student. Two students are then engaged in discussion with the teacher on the issue. The first student mental processes can be "triggered" by the second's contribution, and get a chance to complete a positive verbal interaction with the teacher and second student. Other methods include small group discussion, mooting, debating and other techniques explored in this section which are designed to facilitate participation.

Pyramiding (sometimes called "snowball groups") is a marvellous teaching method which ensures that students learn through activity and interaction with others. It involves students in class first working alone, then in pairs, then in fours, and so on. ${ }^{80}$ The normal conclusion to the exercise is to have students involved in some form of activity involving the pooling of the conclusions or solutions of the groups. Students can focus on creative responses to the task without worrying about avoiding being chosen to report immediately to the whole class, but with enough of a social obligation to produce an outcome so that they can report to their neighbour. The method also avoids a problem often found with "buzz groups" where students begin the activity with no ideas of their own. Consequently they spend the beginning of the "buzz group" session reading their notes, and find it difficult to get talking. If students are given an opportunity to work on their own for a while they are more likely to start a useful discussion. Students working in pairs are also likely to be more creative and adventurous with their ideas, because the fear of humiliation is reduced. In addition, groups of four to six may find it difficult to get talking immediately, particularly if they have been passively listening to a lecture. Time spent thinking alone, and then a discussion with just one other person, makes it easier for group 
discussion to make some progress.

Pyramids are most effectively used when there are different instructions to students working on their own, and then in pairs, and then in the larger group of four or more. This enables all the basic steps of problem-solving to be worked out by the time the larger group tries to deal with the problem. Instead of the larger group prematurely closing down options, the problem or issue can be considered from the beginning and various alternatives developed before a resolution is sought. Pyramiding also has the advantage that it enables the group to tackle tasks that are extremely daunting and complex to students if attempted in one go. Pyramiding makes complex tasks more manageable, especially when each stage is accompanied by a progressively more complex and demanding task which builds on the achievement of the previous stage. For example, students can be asked individually to spend a few minutes identifying the crucial facts, legal principles and practical and ethical constraints involved in resolving a legal problem. Then in pairs they can be asked to compare notes, form a basic agreement about the important points, and begin resolving the problem without expecting to complete the task. Each pair can then be asked to team up with another pair, and each pair explains to the other what they have done thus far, and to compare their approaches. They then set about resolving the problem. After the time allotted for this task has expired, the whole group comes together in one session, and one group of four is asked to explain their answer to the problem or question. The other groups are then asked if they took a different approach, and these different approaches are discussed in the plenary session. ${ }^{81}$

A great advantage of pyramiding is that as students get into larger groups they find that their assumptions and solutions to the problem are challenged by other students who have dealt with the same issue but alone or in a different pair. Students quickly begin to see that there are different approaches, assumptions and value judgments involved in the task they have been set. ${ }^{22}$ The quality of the reporting to the whole class is also likely to be better once students have rehearsed the ideas in small groups, have already spoken in a group, and are able to feel that they are not directly responsible for the ideas generated by the group.

Co-operative learning is an extremely effective teaching 
method and involves students learning by teaching their peers. For example, the "learning cell" method involves pairs of students alternating in asking and answering questions on materials they have both read. Students prepare by reading assigned materials and while so doing they write out questions dealing with the major points in the reading. In class, one of the pair begins by asking the other student a question. The other answers the question and if necessary is corrected or given additional information. Then the second student asks a question of the first student, and the process continues. ${ }^{83}$

The procedure can be varied by asking each of the pair to read different materials. Each then has the task of "teaching" the other the essentials of her or his reading, and asks the person being taught prepared questions.

"Socratic Dialogue" or the "Case Book" method. Here the teacher conducts the class by calling upon a particular student to answer questions pertaining to cases or other materials which all students are expected to have read before the class. This typically involves the teacher calling on students to recite the facts of a case. If there is an adequate response to the question, the teacher then asks a series of supplementary questions about the reasoning of the case until the student can no longer answer, when another student is questioned and may resolve the problem by rejecting one or more of the first student's assumptions. ${ }^{84}$

While the Socratic method does enable students to be involved in genuine problem solving situation where they can observe the teacher engaging in legal discourse in an enculturating fashion, as practised in law schools, it has a number of serious weaknesses. As Hantzis ${ }^{85}$ points out, this method of teaching is exclusively male in its approach and the classroom is "awash with silent tension" while this method is used. Many, if not most, students find the case book method threatening, particularly when the teacher calls on students by name and spend very little of their time thinking creatively about the subject matter. The use of the case book method therefore undermines any attempts to develop a relaxed class atmosphere which encourages risk taking and free thought. It silences and inhibits certain groups of students, particularly women and students from Asian cultures. ${ }^{86}$ In its pure form it focuses on legal doctrine to the exclusion of policy, theory or interdisciplinary perspectives, 
and therefore elicits question begging doctrinal responses. Far from encouraging students to explore and develop their values, it stifles such developments. It also focuses too much on individuals, with the consequence that the teacher is usually unaware of whether the experience is enhancing the learning of others.

"Brainstorming". This is a technique in creative thinking in which class members generate as many answers as possible to the question or problem raised by the teacher. The "answers" are recorded on a whiteboard, ${ }^{87}$ or even overhead projector, by the teacher, or a student nominated from the body of the class. ${ }^{88}$ Critical judgments are suspended until all ideas are generated. What counts is the quality of ideas - the more ideas there are, the more likely it is that there will be good ideas. The wilder the idea the better, and if it is possible to develop someone else's idea, so much the better. Only once all the ideas have been generated should there be some critical discussion of the issues raised.

This teaching method is an extremely useful way of changing the pace in a class, of stimulating student participation and thought, and of developing the creative side of students. It can help students develop new perspectives, and can facilitate discussions where students are asked to think differently about an issue, or to use their own experience or instincts to deal with a particular topic or problem.

Mooting is a particularly good "authentic activity" for law students. Particular class members are selected, either before or during the class, to present as best they can, each side of an argument or case. The rest of the class will be expected to decide which party "wins" on the facts and on the law. The obvious advantage of this approach is that it teaches students how to prepare and present legal arguments, and helps them develop oral skills and to meet arguments raised by others.

Mooting can very easily be turned into a group activity by getting groups of students to prepare the argument in buzz groups, and by encouraging them to switch speakers when the speaker holding the floor runs out of ideas. They will all be responsible for the argument, and at the same time will learn how to work cooperatively with others. Similarly, the class can be divided into two, one to argue for one party and one for the other. Some 
students can be assigned to the bench, to play the role of majority or dissenting judges, who will interrupt arguments with questions. If preceded by a short small group discussion between students to get them involved in the activity, this method ensures full participation of the class. ${ }^{89}$

Simulations or role playing involve the teacher assigning students to particular roles and providing instructions indicating how these roles are to be played out. ${ }^{90}$ They enable students to understand practical aspects of the operation of the law, to explore their own values and assumptions in relation to law, or to find out about the "internal logic" of a situation in which a lawyer may be placed. They also enable students to learn, in fairly authentic situations, important skills, such as drafting or negotiating. Participants should carefully follow their instructions, and should immerse themselves in the role they are playing, and if need be indulge in some risk taking.

Symposium discussion. This is a discussion in which a topic is broken up into a number of phases, and each part is presented by a person who has spent a bit of time researching a particular point, and who gives a very short and concise summary of the fruits of their inquiry. This can be followed by general discussion. Many teachers find it useful, in reasonably small classes to ask from one to three students to take particular responsibility for presenting the material to be discussed in a particular class, and to lead and stimulate the ensuing discussion. This does not excuse the other students from reading for class. This method helps shift the responsibility for learning on to students, and helps to develop presentation skills. It also develops skills in analysing and synthesising material. This teaching method should not, however, be used indiscriminately. If all the students in the class are expected to read the material being presented, the presenting students must ensure that they develop the material in some way, so that they do not merely paraphrase what the others have already read. The method also has the disadvantage that bad presentations can cause boredom amongst other members of the class. To avoid this occurring, students should be aware that they will be expected to further develop the material being presented, to raise issues not covered by the presentation, or to question the presenter. This is 
best done by foreshadowing small group discussion on the topic being presented. Another possible follow up method is to assign certain students to comment on the presentation.

A variant on this is debate discussion where class members debate two sides of a controversial issue. Each person is given a limited time to speak, and must attempt to persuade the audience, rather than denigrate her or his opponent. This can be done by convening the class as a legislative body to decide whether to adopt certain legislation. The class is divided into groups, each representing a group with a special interest or lobby group, and arguing for or against the proposed legislation. Again, the groups should first convene alone, to sort out their position and to prepare their arguments. After hearing from the representatives of all the groups, the legislature convenes. The class members abandon their previous roles and debate the appropriate legislative action. ${ }^{91}$ Alternatively, the debate and the small group discussion can be combined by dividing the class into groups of three or six students, with three roles. The first role argues for a certain position, and the second role argues against it. The third role takes notes and makes the decision, and reports to the class about the arguments made and the decision. ${ }^{92}$

Reading, or related activities which involve learning from the written word, both in and outside class, are extremely important methods of teaching, particularly in a discipline such as law. One of the outstanding characteristics of a lawyer's working life is the demand placed on her or his capacity to absorb huge amounts of new information. which has its source in the written word. Lawyers who are visually impaired will have to develop their own arrangements and methods for dealing with the written word, and law school is a good place to develop this process.

The independent absorption of written material therefore should be an integral part of all legal education. Not only is this activity a crucial skill to be learned by lawyers, but it is one of the foundations of participative learning. Material can be read several times faster than it can be absorbed aurally. It is also a more flexible method. Written material can be reread, note taking is more productive and stimulating, and there is more opportunity for critical scrutiny. There is more benefit in students carefully reading a good text than listening to a lecture. As noted earlier, lecturing is 
an inefficient means of achieving what its adherents believe to be its purpose - the passing of information from teacher to student. It also puts the teacher strongly in the position of "expert" or "authority", thereby inhibiting other teaching styles that may be more useful to achieve the teacher's objectives.

Of course, the choice is not between lecturing or reading, but the combination used. The use of "lecturing" in class should complement students' own reading of the basics of the topic, and should provide elaboration, clarification of difficult points and commentary. Good selection by teachers of reading material for students will enable the teacher to spend less time in class on the basic cognitive skills and can provide the basis for classroom activities aimed at achieving other learning objectives.

Put in this context, it seems clear that the careful selection of appropriate reading material is crucial to the use of teaching methods that encourage student participation. If teachers expect students to read before class, student preparation time should be spent reading, not hunting for materials in libraries. Teachers should therefore ensure that students have in their possession the material to be read. If teachers wish students to develop library and other research skills, research assignments aimed at these ends should be set, or selected research exercises should be set for class.

Not only should students have easy access to the required reading, but the teacher should make the reading as accessible as possible. The aim is to promote and to facilitate as much independent learning as possible by students outside the classroom, not to provide students with obstacles to test their tenacity and commitment. Students should therefore know why they are reading the material, how it fits into the rest of the course, what they should be looking for or thinking about in the text, and the kinds of issues or questions they should be considering when they read the material. They might also be asked to think about problems before coming to class. Of course, it may be that the teacher wishes students to read unedited cases, articles or other materials, so that they can develop the ability critically to read, analyse and assimilate new material. If this is the case the purpose of the exercise should be communicated to students.

This background and the instructions, questions and reading hints should be provided in the materials themselves or in an 
accompanying reading guide. It should also be reinforced orally in the class where the reading is assigned. In short, students should know why they are reading the material, how it relates to the course and its objectives and how it will be used in class. The reading guide should also be structured to enable students to plan when they will do their reading. If they have advance notice of when reading will be required, they are given the opportunity to plan when to do the reading, and can build it into their weekly, or even monthly routine.

Materials distributed to students should be carefully edited by teachers before the materials are distributed. Only relevant material should be included. This will usually involve editing out parts of an extracted article or case which is irrelevant to the objectives of the reading. Cases should not be over-edited. Students should be able to read an edited case in its proper factual and procedural context.

Of course, if the objective of the extract is to require the students to determine what is or is not relevant in the extract, then the whole extract should be included. But students get frustrated and disheartened if they do not know why their reading is relevant, and cannot see how it relates to the course, and so this approach should not be over-utilised. The overall strategy should be to ensure that students enjoy reading for class, and that they feel that it is worthwhile. Only then will reading for class become part of the learning culture.

If the use of pre reading is not just to focus on the lower levels of the cognitive domain, and if it is not merely going to reinforce a narrow "black letter" approach to learning the law, reading materials should not just include extracts of cases and statutes, but should include other kinds of material that provide insights to the richness of law as a social phenomenon. Materials should be chosen so as to include articles providing multidisciplinary perspectives on the topic, should provide empirical data on "the law in action", 93 multicultural perspectives and materials reflecting attitudes to the law that are different from those expressed by white, middle class male lawyers. Law affects all members of society, and lawyers will have to deal with all those affected by law. Lawyers should therefore be educated in these different perspectives, and therefore need teaching materials to expose them to different "voices". When cases are included they should be 
chosen so that they do not reinforce stereotypes about women, persons with disabilities, and non-mainstream cultural groups. ${ }^{94}$

Teaching materials can be designed and complied by teachers to involve students in self study activities that are problem based or are aimed at developing skills. For example, the materials can set out situations in which students are required to engage in the kinds of activities that lawyers regularly carry out, such as drafting a contractual clause, or construing a clause in the light of legal principles which have been read prior to the activity. Students can be required to read an article on some aspect of socio-legal research and then asked to draw up a research program based on their reading prior to coming to class.

Reading need not be confined as a teaching method to pre class activities. Reading can be used as a teaching method in class, to change the pace of the class, or as a means of preparing students for a later activity in the class. For example, most of a class can be focused on a case study or fact situation requiring analysis and a "solution". Students can be given the case study or problem in class and asked to read it before discussing it in small groups with other students prior to full class discussion. Alternatively, students can be given time to read new material before a full class discussion on the topic, or small group exercises.

The importance of using reading materials to promote independent learning outside the classroom becomes apparent when teaching methods in large classes is considered. Traditionally tertiary teachers have argued that participatory methods are not possible in large classes (over one hundred students). The main reason given to support such a view is usually that "it is difficult to get discussion going in a large class" and that the teacher still has "to get the material across" and that discussion, even if it is successful in a large class, slows down the class. If, however, the content of the course "gets across" through the use of materials designed to promote and support independent learning, and "class discussion" is backed up or even replaced with some of the other participative methods outlined above, particularly the use of pyramiding, debates, and syndicate groups, with mini lectures used to reinforce material and to tie topics together, then the dynamics of large group teaching can be radically altered. Students will be motivated to read well thought out materials before class, and will 
know that when they come to class they will have an opportunity to achieve the whole range of teaching objectives. It seems impossible to change the traditional approach to large group law teaching in law schools unless law teachers rethink entirely their teaching method, and work out what can be done most effectively outside class, and what can best be done in class. Participative teaching methods can be used in class by teachers who understand these methods, have practised them and are confident with them, and restructure their courses and materials to focus on methods to promote independent learning outside class.

Another teaching method that is overlooked in this context is the manner of assessment of student performance. The importance of assessment is that it does more than certify that students have achieved a certain level of competence. It directs their learning activities, and focuses their attention directly on learning particular skills, methods and materials. It is well known that students tailor their learning to the form of assessment that is being used in the course. All forms of assessment require students to learn on their own, and so good teaching will ensure that courses are assessed in a manner that is not just aimed at certifying that students have reached the requisite standard of competence, but in a way that enables students to achieve important learning objectives through independent study and research. Three hour end of year examinations for example, lead students to cram information into their short term memories, and at best ensure that students "practise" answering problems on old examination papers. At best students focus on the lower levels of the cognitive domain. Very few other skills are developed, and in particular the objectives dealing with values and motivation to learn are ignored. Students can be required to write essays in examinations, but these invariably do not promote reflective and well thought out arguments, unless students have some advance idea of the question. Therefore it is more appropriate to develop other forms of assessment that develop research skills, skills in synthesis and evaluation, and which enable students to explore their interests, attitudes and values. Teachers should therefore, consider a careful blend of assessment covering examinations, class participation, essays and assignments, and mooting or debating. Assignments and essays should not just involve library research, but should also 
involve students talking to participants and users of the legal system. The choice of assessment should be linked to learning objectives, not expediency.

Good teaching, as has been noted earlier, requires teachers to evaluate whether they have achieved what they set out to do in designing their curriculum and choosing their teaching methods and methods of assessment. Teaching methods are only successful if they enhance student learning. Care should therefore be taken to use a variety of methods to evaluate the impact of the teaching on student learning. ${ }^{95}$

\section{CONCLUSION}

The previous section of this paper has argued for a broadening of teaching methods away from the traditional classroom methods of the lecturing and the "case book" method. The "trade school" origins of Australian law schools have resulted in a "content" focused teaching method which emphasises knowledge of the positive law. Classroom teaching methods need to be aimed at ensuring that students learn through activity inside and outside the classroom, and indeed, actively learn by problem solving, discussion, experimentation, reflection, observation, intuition, as well as abstract thought. Good law teaching should broaden its focus away from simply cognitive objectives towards the all round development of students' intellectual skills, their values, their attitudes and their interests.

In other words, law teaching should be adopting a more "student focused" activity based approach, and Australian law teachers need to tailor their teaching methods to their objectives, and their students' needs. Of course this needs to be done within the limits of the teacher's skills, ability and personality. These however are not necessarily fixed. Law teachers can learn new methods and new skills, and can reshape their teaching materials to promote independent student learning (particularly in relation to knowledge of the substantive law or of multidisciplinary perspectives) prior to class activity so as to enable class time to be utilised for different activities facilitating the attainment of different learning objectives.

Teaching styles and methods will need to be varied according to the students being taught and the learning objectives being pursued. 
In activities designed to achieve the cognitive objectives of analysis, application, and synthesis, teaching methods such as simulations, role plays, buzz or syndicate groups, pyramiding, and mooting, or a combination of these, can be used to give students an opportunity to do these things themselves and to see them being done by others, including the teacher. They develop important communication and interpersonal skills, and allow students to get to know their colleagues. These methods should not be used as ends in themselves, but only with clear purposes which should be communicated to the class. If students do not appreciate why they are using a particular method, they may resist its use. Wherever possible the teacher should provide diagnostic feedback on student performance, and prompt, encourage and support students.

Writing skills should not be ignored in teaching. Courses should aim wherever possible to provide students with the opportunity to undertake research essays and assignments, and these should be returned to students as promptly as possible with as much feedback on the student's performance as possible. Writing skills can also be developed by encouraging students in their own time to attempt old examination papers, and arranging sessions where there can be general discussion of acceptable approaches, and where students can swap papers and "mark" the written answers. Students will learn a great deal from assessing the efforts of their fellow students under the supervision of the teacher.

In relation to the objectives focusing on values, the crucial role of the teacher is to provide an example for students in exploring their own values, attitudes and interests. The teacher should be open about her or his own attitudes, values and interests, but at the same time must be sensitive enough not to impose the content of these onto sometimes impressionable students. The teacher should display open mindedness and a commitment to tolerance and pluralism, so that students accept that there are a variety of different attitudes, values and interests, and respect their expression by others. Students should however, be encouraged to test and justify their opinions and to explore and understand others, rather than spending their time blindly defending an adopted position. This cannot be done without a good example being provided by the teacher, and without materials that raise the issues to be explored. It is also assisted, particularly in very big classes, by the use of buzz 
groups and pyramiding, where students can explore their values and attitudes away from the scrutiny of the whole class.

Senior Lecturer in Law, University of Melbourne. I am grateful to my colleagues in the ALTA Law Teaching Workshop and at the Law School, University of Melbourne for their interest in law teaching, for their influence on my thinking and for their support. In particular, I would like to thank Ben Boer, Graeme Cooper, Marlene Le Brun, Hilary Charlesworth, Jenny Morgan, Ian Malkin, Rosemary Hunter, Richard Ingleby, Sarah Biddulph and Veronica Taylor.

(C) 1992. (1992) 3 Legal Educ Rev 17.

1 Parliament of the Commonwealth of Australia, Senate Standing Committee on Employment, Education and Training, Priorities for Reform in Higher Education (Canberra: AGPS, 1990) (xiii) at 3. See also Chapters 1, 2 of the Report.

$2 \quad$ Id (xiii) at 3.

3 Id at (xiv). See also Chapter 3.

4 P H Partridge, The University System, in Melbourne Studies in Education 1960-1961, (Melbourne: Melbourne University Press, 1962) 534 quoted in the Senate Standing Committee Report, supra note 1.

5 M Chesterman \& D Weisbrot, Legal Scholarship in Australia (1987) 50 Mod L Rev 709, 710. See also D Pearce (chairman) Australian Law Schools: A Discipline Assessment for the Commonwealth Tertiary Education Commission (Canberra: AGPS, 1987); and JH Wade, Legal Education in Australia Anomie, Angst and Excellence (1989) 39 J Legal Educ 189.

6 Chesterman \& Weisbrot, supra note 5. There is an irony in these criticisms of legal education as being too focused on the profession. It is not uncommon for members of the profession itself to complain that law schools do not do enough to equip law students for legal practice. This suggests that traditional legal education is caught between two poles - it does not teach "practical" legal skills, and it does not adequately educate students in broader legal theory. This point will be dealt with in the discussion of situated learning. Id at 711 .

8 Id.

$9 \quad$ Id at 712

10 Id at 713.

11 Id at 718.

12 G Gibbs, S Habeshaw \& T Habeshaw, 53 Interesting Things To Do In Your Lectures (Bristol: Technical and Educational Services Ltd, 1987) at 9.

13 For a discussion of the "case book method see EW Paterson, The Case Method in American Legal Education: Its Origins and Objectives (1951) $4 \mathrm{~J} \mathrm{Legal} \mathrm{Educ}$ 1; EM Morgan, The Case Method (1952) 4 J Legal Educ 379; JO Cole, The Socratic Method in Legal Education: Moral Discourse and Accommodation (1984) Mercer L Rev 867. For further discussion of the Socratic method, see infra at 48.

14 The next part of this paper will argue that it is no longer possible to ignore the research indicating what good teaching is all about.

15 See again the comment in note 6.

16 J Broadbent, Under My Groaning Voice: The Management of Teaching (1977) 31 New Univ Q 421 at 426.

17 R Cotterrell, The Sociology of Law: An Introduction (London: Butterworths, 1984) at 3.

18 See infra. 
See generally DR Lehman \& RE Nisbett, A Longitudinal Study of the Effects of Undergraduate Training on Reasoning (1990) 26 Dev Psych 952- 960, at 953. Newman, BE Ringwald, JW Ringwald \& R Rozenwen The College Classroom: Conflict Change and Learning (New York: Wiley, 1970) at 144-233; AF Grasha, Observations on Relating Teaching Goals to Students' Response Styles and Classroom Methods (1972) 27 Am Psychologist at 144-7; S Reichmann \& AF Grasha, A Rational Approach to Developing and Assessing the Construct Validity of a Student Learning Style Scales Instrument (1974) 87 The J of Psych 213-223. See also WH Bergquist and SR Phillips, Handbook for Faculty Development Vol I (San Francisco: Jossey Bass, 1978), ch 2.

40

These categories tend to overlap with gender stereotypes and should therefore be viewed with caution. Nevertheless the categories do reveal the diversity of student attitudes to learning in the classroom, and their gendered nature suggests that it is very important to develop teaching methods to deal appropriately with the different categories. 
41 This corresponds with Grasha's and Reichmann's category of "dependent" students supra note 39.

42 Indeed, I am conscious that in the description of the different types of students found in the classroom, the categories themselves are imbued with notions of gender and gender stereotypes.

See for example, R Mann et al, supra note 39 at 1-19. See also Bergquist and Phillips, supra note 39, Chapter 2.

44 Mann et al, supra note 39 at 1-19.

45 J Adelson, "The Teacher as Model" (1961) 30 The Amer Scholar 395-398, 400-401.

46 Id.

47 Id.

48 Supra note 45.

49 Mann et al, supra note 39 at 1-19.

50 See J Axelrod, The University Teacher as Artist (San Francisco: Jossey Bass, 1973) at 12-14.

51 Mann, supra note 39 at $1-19$.

52 Bergquist \& Phillips, supra note 39 at ch 2.

53 Id.

54 Id.

55 Id.

56 J Seely Brown, A Collins \& P Duguid, Situated Cognition and the Culture of Learning (1989) 19 Educ Researcher 32. The following discussion of situated learning is drawn very heavily from this article.

57 Id.

$58 \quad I d$.

59 Id.

$60 \quad$ Id at 33.

61 Id at 33. For examplc, carpenters and cabinetmakers use chisels differently; physicists and engineers use mathematical formulae differently.

62 See C Geertz, Local Knowledge (New York: Basic Books, 1983).

63 Seely Brown, Collins \& Duguid, supra note 56 at 34.

64 Id.

65 Id at 37. See Seely Brown, Collins and Duguid, supra note 56 from 37 onwards for two examples of this kind of learning in the field of mathematics.

66 Id at 39.

67 Id at 37.

$68 \mathrm{Id}$.

69 Id at 39 and see figure 3 at 40.

70 For an excellent review of research into the effectiveness of teaching methods, see WJ McKeachie, Research on College Teaching: The Historical Background (1990) 82 J of Educ Psych 189.

71 See for example, D Bligh, What's the Use of Lectures? (Harmondsworth: Penguin, 1972) and G Gibbs, Twenty Terrible Reasons for Lecturing (Standing Conference of Educational Development, Occasional Paper No 8, January 1982).

72 See infra at 150.

73 Gibbs, Habeshaw \& Habeshaw, supra note 12.

74 See generally $\mathrm{T}$ Makin-Slaughter, Teaching with Media (University of Melbourne: Centre for the Study of Higher Education, 1990); VR Johnson, 
Audiovisual Enhancement of Classroom Teaching: A Primer for Law Professors (1987) 37 J of Leg Educ 97; H Charlesworth \& R Johnstone, Show and Tell: A Primer on the Use of Overhead Projections in the Law Class (1990) $10 \mathrm{U}$ of Tasmania L Rev 59.

See infra at 44-45.

76 J Centra, Determining Faculty Effectiveness (San Francisco: Jossey Bass, 1979).

77 See S Wildman, The Question of Silence: Techniques to Ensure Full Class Participation (1988) 38 J Leg Educ 147; T Banks, Gender Bias in the Classroom (1988) 38 J Leg Educ 137; and J Morgan, The Socratic Method: Silencing Cooperation (1989) 1 Legal Educ Rev 151.

Wildman, supra note 77 at 151.

79 Id at 152 .

80 See generally Gibbs, Habeshaw \& Habeshaw, supra note 12 at 121-4.

81 For an example of this see Gibbs, Habeshaw \& Habeshaw, supra note 12 at 123-4.

82 See again the basic principles of cognitive apprenticeship outlined above.

83 ML Goldschmid, The Learning Cell: An Instructional Innovation (197l) 2 Learning and Development 1-6.

84 For a very interesting discussion of the usefulness of the Socratic method, see A Collins, "Processes in Acquiring Knowledge" in RC Anderson, RJ Spiro \& WE Montague, Schooling and the Acquisition of Knowledge (Hillsdale, New Jersey: Lawrence Erlbaum Associates, 1977) 339. See also CW Hantzis, Kingsfield and Kennedy: Reappraising the Male Models of Law School Teaching (1988) $38 \mathrm{~J}$ Leg Educ 155 at 156; J Morgan, supra note 7. See also the references supra in note 13.

85 Hantzis, id at 156.

86 Morgan, supra note 77.

87 Electronic copyboards are most useful in this context, as they enable copies of class contributions to be made and then distributed to the class.

88 This has the advantage of allowing the teacher to focus on generating answers.

89 Wildman, supra note 77 at 152.

90 R Ingleby, Translation and the Divorce Lawyer: Simulating the Law and Society Interface (1989) 1 Legal Educ Rev 237.

91 Wildman, supra note 77 at 153.

92 Id.

93 For example, official statistics on prosecutions, penalties imposed, cases litigated, cases settled etc; data from empirical studies of the law; or data simply collected by the teacher for analysis by students.

94 See MJ Frug, Re-reading Contracts: A Feminist Analysis of the Contracts Casebook (1985) 34 The American Univ L Rev 1065.

95 See generally Ramsden \& Dodds, supra note 31, Ramsden, supra note 28, and Johnstone, supra note 31. 